\title{
PUBLIC ENGAGEMENT TOWARDS SUSTAINABLE HERITAGE PRESERVATION
}

\section{MARÇAL Helia ${ }^{1}$}

${ }^{1}$ Integrated researcher, Instituto de Historia da Arte, Universidade Nova de Lisboa, Portugal

https://orcid.org/0000-0002-0476-5233

ABSTRACT: Nowadays, heritage conservators are required to have not only a wide variety of technical but also social and human skills. The shift from a material-based conservation to an approach that focuses on subjects instead of objects (Muñoz Viñas, 2005, p. 147) is a structural approach in contemporary theories of conservation. This tendency towards subjectivity created many possibilities by exposing the multiple perspectives that surround a conservation object. At the same time, it made very clear that conservation objects are contextual and contingent (Clavir, 2009, p. 141). This dichotomy between the tangible and intangible features of a conservation object, however, has been successively overlooked in most conservation endeavours. Prior to the conservation decision-making, institutions usually identified the main stakeholders, with publics and communities being part of that sphere together with owners, artists, and conservators, among others. The decision-making process, however, does not engage with communities in practice. This situation is very problematic for the conservation of cultural heritage objects in general, but it becomes truly hazardous for the preservation of cultural heritage with strong intangible features, such as social artistic practices, ethnographic objects, public art, participatory or performance art or even built heritage, which necessarily involves strong cooperation with communities and artists. After all, to whom are conservators preserving cultural heritage? What is the purpose of conserving cultural heritage for "future generations" if "present generations" are not called to decide in that process? This paper attempts to reflect upon these questions through histories around two buildings in Lisbon that had relevant roles during the Portuguese dictatorship (1933-1974).

KEYWORDS: Public engagement, sustainability, built heritage, social justice

\section{Introduction}

Sustainable development and sustainability have been increasingly mentioned in political discourses worldwide. The limited amount of resources has intensified worries not only about how we use them, 
but also about who gets to use them. ${ }^{1}$ The same is also happening in the conservation of Cultural Heritage. Talks about 'green' approaches to the conservation of objects have been paramount in the last years. The American Institute of conservation (AIC), for example, has created a Sustainability Committee in 2008, due to the apprehension about the effect practices of conservation might have in the environment:

Conservators utilize resources whose production, use, and disposal can have cumulative, sometimes irreversible consequences, such as air and water pollution, deforestation, thinning of the ozone layer, unnecessary plastic waste, and the use of non-renewable energy. We must educate ourselves and build awareness of our impact on the environment and one another. (AIC, 2018)

Other authors and institutions share this concern, and have argued for the sustainability of conservation treatments either through the use of products which are less hazardous for the environment, by creating new innovative methods (see Prati et al., 2017 for an example) or by finding ways to make treatments more durable (see de Silva \& Henderson, 2011 for an overview of how the museum sector has dealt with those issues).

At the same time, more and more scholars (particularly from Critical Heritage Studies - see Harvey, 2001, for example) consider Cultural Heritage as a resource in itself. This inevitably leads to discussions about how we use it, in which ways we are exploring it, and who gets access to this resource. Drawing on previous studies from the field of Critical Heritage Studies and conservation (in the expanded field, understood as a set of actions aiming at preserving cultural heritage), this paper explores the notion of Cultural Heritage and its preservation while arguing for communities' engagement in conservation's decision-making process. ${ }^{2}$ The uses of two historical buildings from Lisbon will be discussed in relation to this theme.

\section{Two historical places at the core of the city}

Portugal, April 25 $5^{\text {th }}, 1974$.

After forty-one years of dictatorship, Portuguese people occupy the streets of Lisbon demanding a political change. This movement, also known as The Carnation Revolution, although planned by the left-wing military, is characterized by its great popular participation, and by being one of the few pacifist military-coups that happened in the $20^{\text {th }}$ century. This dictatorship period (1933-1974), called Estado Novo, is characterised by great military oppression, with intense censorship, and prosecution of regime opponents, which were often imprisoned and tortured by PIDE, the International and State Defense Police (in Portuguese: Polícia Internacional e de Defesa do Estado), the regime's police, which

See, for example, the 2030 Agenda for Sustainable Development, created by the United Nations, which puts forward goals related to resource distribution on par with goals related to access to those resources. Goal 16 - "promote peaceful and inclusive societies for sustainable development, provide access to justice for all and build effective, accountable and inclusive institutions at all levels" (UN A/RES/70/1) - is worth mentioning regarding Cultural Heritage conservation and management.

2 For a discussion about how this issue affects performance-based artworks see Marcal and Macedo 2017. 
became known as DGS after 1969.

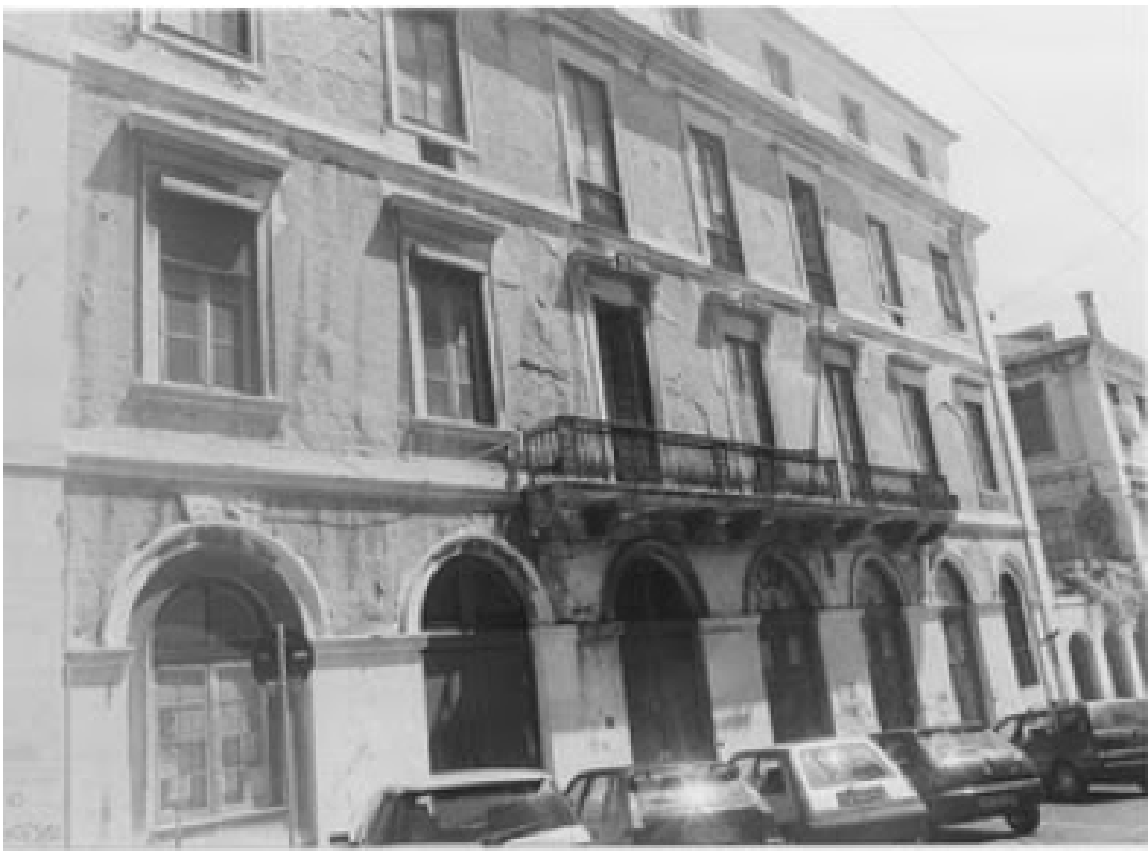

Fig. 1 Building at António Maria Cardoso Street, 22, Lisbon. Former headquarter of PIDE/DGS (until 1974). Photo: available at https://desenvolturasedesacatos.blogspot.pt/2011/05/excertoshistoricos-tenebrosa-pide.html

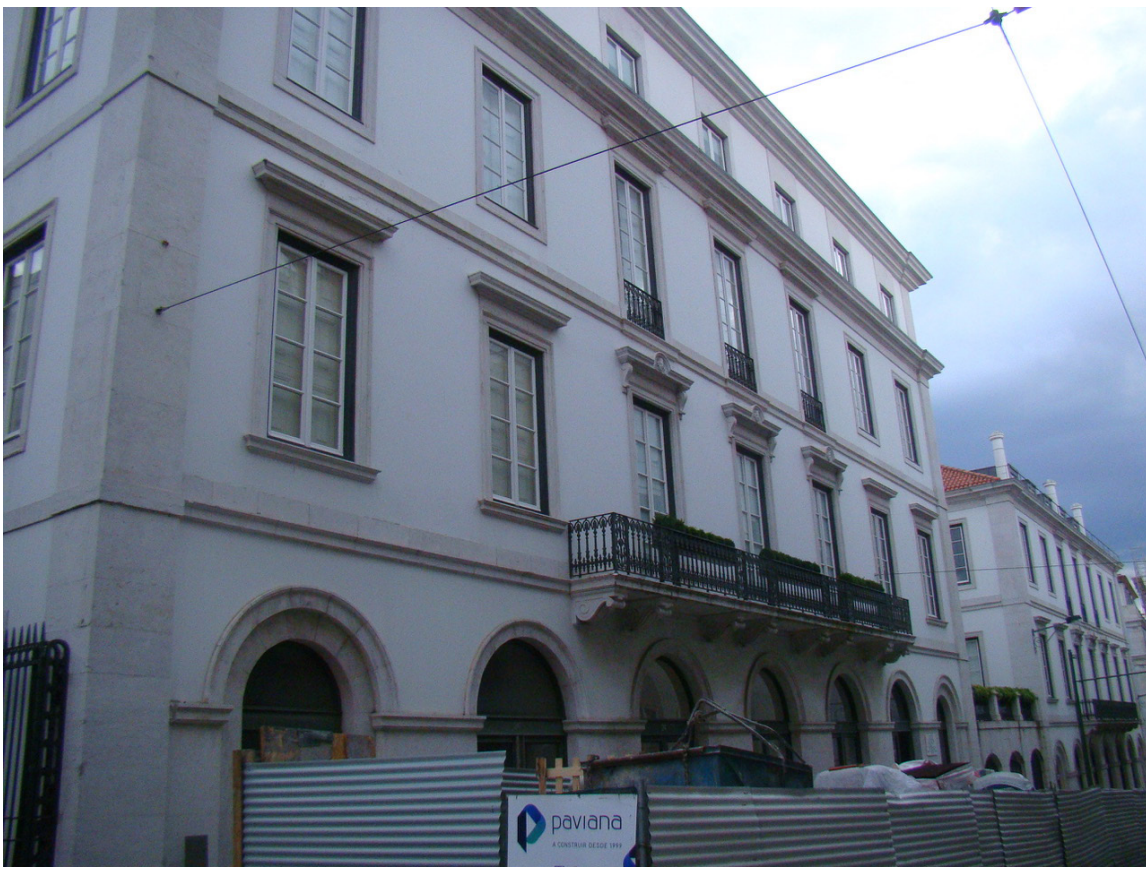

Fig. 2 Building at António Maria Cardoso Street, 22, Lisbon, after its restoration, and again under construction. Photo: Gil Marçal 
PIDE's (and DGS's) headquarters, located at António Maria Cardoso Street in Lisbon (Fig. 1), was the stage of many episodes of torture and even painful death. For many people that lived in that period, this address, this building, its front, and its interiors, are a symbol of repression and revolution. The number 22 of António Maria Cardoso Street, in Lisbon is now a luxury condo (Fig.2). For the generation that was born after the revolution (and after the turbulent revolutionary process that lasted until the 1980s), this is just one more building in a busy street at the heart of Portugal's main city. This erasure of the building's history and of the memories of the community became even more drastic after the removal of the commemorative sign, which referred to the events of April $25^{\text {th }}, 1974$, in 2010 (due to the rehabilitation of the building) and in 2014 (after a robbery - see Figures 3 and 4). After the second removal, Lisbon's municipality interfered, and added a new sign, aiming at encouraging the preservation of memories of the building (Boaventura, 2014). The sign, however, lists the names of the people that were killed during the Carnation Revolution and does not mention the previous function of this heritage site.
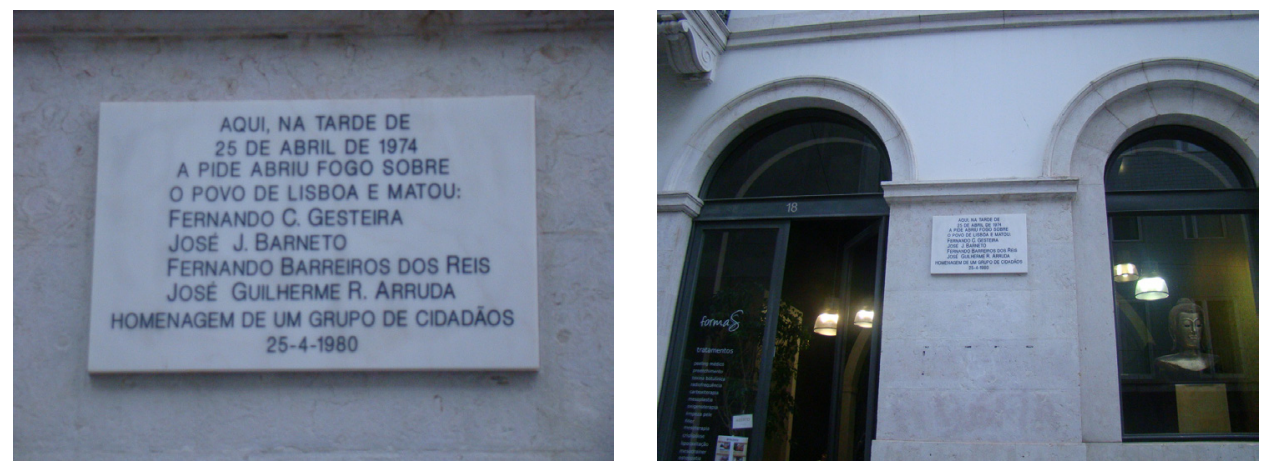

Fig. 3 Commemorative sign present on the walls of António Maria Cardoso Street, 22, Lisbon until 2010 (photograph available at https://desenvolturasedesacatos.blogspot.pt/ 2011/05/excertoshistoricos-tenebrosa-pide.html). Translation to English, by the author: "Here, in the afternoon of April 25th 1974, PIDE opened fire on Lisbon's people and killed: Fernando C. Gesteira, José J. Barneto, Fernando Barreiros dos Reis, José Guilherme R. Arruda. An reverence from a group of citizens 25-4-1980". Photo: Gil Marçal

Fig. 4 Positioning of the commemorative sign in the building. Photo: Gil Marçal

Within a 15-min walk in the direction of Lisbon's Castle (Castelo de São Jorge), it is possible to find Aljube's prison, which was used by the PIDE until 1965, when it was closed after multiple complains, including from the International Amnesty (Oliveira, 2012 - see Fig. 5). In this prison, political prisoners were held and tortured for months, frequently living in small cells where they had to be permanently seated. Among its prisoners, it is possible to account for Miguel Torga, Álvaro Cunhal, and Portugal's former Prime Minister Mário Soares. Aljube is also one of Lisbon's oldest buildings, as it is one of the few structures that resisted to 1775's earthquake. Nowadays, Aljube's prison is Aljube's Museum (in Portuguese Museu do Aljube - Liberdade e Resistência - see Fig. 6 and 7). Within its new role, there is a path towards the memorialization of the dictatorship, the resistance, the revolution, and of the multiple voices that are still unheard, the multiple stories that are yet invisible (Museu do Aljube - Resistência e Liberdade, 2015). This intention can be seen in the discourses of the exhibition space, as this museum without physical collection serves a vehicle of testimonies and as a receptacle of 
memories, as well as in the other spaces that are part of this Museum, which includes a documentation centre.
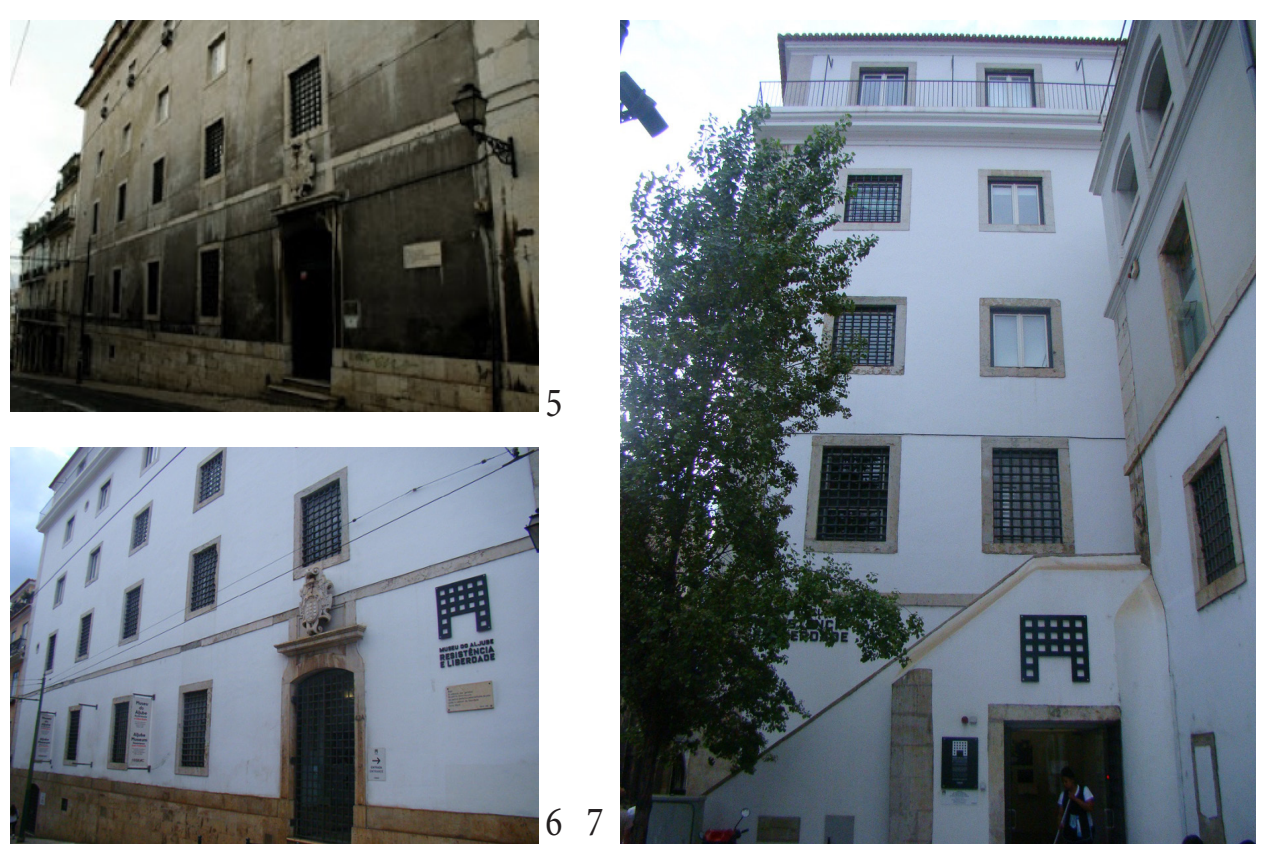

Fig. 5 Aljube's prison (until 1965). Photo: available at http://alvarocunhalbiografia.blogspot. pt/2010/12/moral-do-revolucionario-na-prisao.html.

Fig. 6 Front view of the Aljube's museum, the prison after the renovation. Photo: Gil Marçal

Fig. 7 Lateral view of the Aljube's museum, the prison after the renovation. Photo: Gil Marçal

Comparing PIDE's headquarters with Aljube's prison it is possible to see two building rehabilitations: but while in the first case the memories of the place have been erased, in the second these memories are being praised, transmitted, and continually constructed. While these are extreme cases of erasure and memorialization, they can be used as operative tools in the examination of more nuanced issues that might occur in the conservation of cultural heritage. Where does the "original intention of the artist" ends, and the "social significance" of the object starts? When does conservation stop to be a process aiming at recovering the past, and starts replacing memories? Whose memories are being preserved, and where is the social in the object's meanings? Where lies the conservation decisions around those two buildings?

\section{The politics of conservation: what and for whom is conservation?}

Conservation is currently defined by the International Council of Museums - Committee for conservation (ICOM-CC) as "all measures and actions aimed at safeguarding tangible cultural heritage while ensuring its accessibility to present and future generations". All conservation "measures and actions should respect the significance and the physical properties of the cultural heritage item" (ICOM-CC, 2008). Three main aspects should be taken into account when analysing this brief 
description: (1) conservation is defined as an aggregation of actions targeting the safeguarding of cultural heritage; (2) conservation actions should safeguard both the physical properties and the significance of a given cultural heritage item; and (3) conservation actions are limited to preserving tangible cultural heritage.

Despite this definition and the importance given to the notion of "tangible cultural heritage", the idea of the "intangible" is increasingly permeating the conservation field. In the context of the conservation of Contemporary Art, for example, documenting the artwork's "intangible features" became a conservation action on par with other operations regarding the object's tangible manifestation (Weyer \& Heydenreich, 2005; Wharton, 2005). The documentation of an artwork's "intangible features" included, among other things, remarks about appropriate lighting, the role of the audience, or the artwork's biography (van de Vall et al., 2011) or career (van Saaze, 2013). The need to document or, at the very least, assess the object's "intangible features" became increasingly indispensable as the ritualistic or performative elements of cultural heritage items were acknowledged, as in the case of performance art, public art, or objects from World Cultures (Scholte, 2010). That is also the case of the built heritage that is part of a city's fabric: the becoming of a city is comprised by effects of the past and present communities that inhabit every house, every place. In these contexts, the dichotomy between the tangible and the intangible becomes less clear.

\section{Material-oriented conservation and the notion of tangibility}

Looking at ICOM-CC definition, it is possible to see that the identity of conservation's interdisciplinary field is constructed around the idea of tangibility. "Tangible cultural heritage", however, is an expression lacking definition in itself either in ICOM-CC's Resolution of Terminology for conservation or in the context of conservation's codes of ethics.

ICOM-CC's Resolution on Terminology for conservation, created in 2008 by a Task Force made up of members of the ICOM-CC board, refers to four main terms - conservation (as described above), preventive conservation, remedial conservation, and restoration - but does not examine the other terms used to characterise the object in need of conservation, such as safeguarding or tangible cultural heritage. In the commentary accompanying ICOM-CC's Resolution on Terminology it is noted that conservation actions are acknowledged according to (1) their aims, or "whether they address future deterioration, current deterioration, or past deterioration"; (2) their impact on the material properties and physical appearance of the object; and (3) their sphere of influence, or "whether they can be applied to only one cultural heritage item at a time or to a group of items" (ICOM-CC, 2008). Two main observations emerge from this commentary: (1) the notion of safeguarding is linked to the aim of conservation, and (2) the Resolution was written having a material-oriented notion of conservation 
in mind. These two positions can be seen across conservation's various codes of ethics and definitions, ${ }^{3}$ all of which tend to acknowledge conservation as a material-oriented discipline. In any of these codes or definitions, safeguarding appears as an action involving traditional conservation axioms, such as the idea of minimum intervention or of maintaining the original material, both of which have been contested in recent theoretical explorations. Even if the aim of safeguarding actions resides in the maintenance of the physical properties of the object, it is always possible to count several instances when the "requirements of social use" go against what is expected from the perspective of the material conservation of cultural heritage (see, for example, Muñoz Viñas, 2005, p. 105). And although a cultural object's use seems to be interrelated with its material properties, current codes of ethics and definitions, however, appear to be too general to account for differences in cultures of conservation, that is, of the why and the how a given cultural heritage item is preserved (cf. Ashley-Smith, 2017).

Current codes of ethics and definitions of conservation have been seminal in the establishment of a conservation doctrine, and yet they do not seem to encompass recent theoretical developments. Rather than merely a scientific and seemingly objective materials-based practice, conservation is now recognised as a product of a "socially constructed activity with numerous public stakeholders" (Bracker \& Richmond, 2009, xv-xvi; see also Cane, 2009). And yet, conservation practices, however, still appear to be linked with the materials of cultural heritage. But if conservation is a socially constructed activity, safeguarding is a confederation of socially induced actions. So, in which ways are safeguarding actions being socially constructed? How does it affect in-facto the preservation of the significance and physicality of cultural heritage?

\footnotetext{
The ICOM-CC's The Conservator-Restorer: a Definition of the Profession, for example, posits the conservator as an agent that conserves and restores "cultural property", adding that this activity includes examination, preservation, and restoration (ICOM-CC 1984). AIC's Code of Ethics and Guidelines for Practice assumes that conservation's aims lie in the preservation of cultural property, comprising "material which has significance that may be artistic, historical, scientific, religious, or social, and it is an invaluable and irreplaceable legacy that must be preserved for future generations" (AIC 1994). CAC's and CAPC's Code of Ethics and Guidance for Practice considers that the aim of conservation is "to study, record, retain and restore the culturally significant qualities of the cultural property as embodied in its physical and chemical nature, with the least possible intervention" (CAC and CAPC 2000, 13). The AICCM's Code of Ethics and Code of Practice suggests that conservation targets "cultural material", although it specifies "artworks", a notion to be understood loosely, as one example of what cultural material might be (AICCM 2002). E.C.C.O's Professional Guidelines (II), state that the conservator "shall respect the aesthetic, historic and spiritual significance and the physical integrity of the cultural heritage entrusted to her/his care", while taking into account "the requirements of its social use while preserving the cultural heritage" (Art. 5 and 6, ECCO 2003).
} 


\section{Cultural heritage: conserving the object and its values}

The above-mentioned Codes of Ethics are based on ways of seeing cultural heritage, which is highly dependent on the values that surround - or even define - cultural heritage objects and their significance (Avrami et al., 2000, Clavir, 2009, Revez, 2017). Values, ${ }^{4}$ as stated in the preface of the seminal Report on Values and Heritage conservation, "are critical to deciding what to conserve-what material goods will represent us and our past to future generations - as well as to determining how to conserve" (Avrami et al., 2000, 5). Values are "derived from the meanings and uses that people attach to buildings, sites, and landscapes, and [are] constructed amongst individual, institutional, and community actors" (Avrami, 2009, 179). The Nara Document on Authenticity (ICOMOS 1994) similarly states that "conservation of cultural heritage in all its forms and historical periods is rooted in the values attributed to the heritage" (ICOMOS, 1994). In a values-based approach to conservation (Muñoz Viñas, 2005), ${ }^{5}$ values are fundamental to conservation decision-making (Applebaum, 2009, Avrami et al., 2000, Muñoz Viñas, 2005, Taylor \& Cassar, 2008). Conservator and theorist Jonathan Ashley-Smith points out that values are "a social construct dependent on social relationships [and are] bound to change through time and between cultures" and are "an extrinsic property that cannot be directly detected by the senses" (Ashley-Smith, 1999, p. 81- 82). Values associated with an object are the reason why it is intuitively evident that safeguarding means a very different thing regarding the conservation of a 15th-Century historical manuscript as opposed to last week's local newspaper. They are also the reason why those two buildings in Lisbon would provide a very different discussion if they had not been actors in one of the most problematic periods of Portugal's recent history.

One of the most important steps in any conservation endeavour (in its broad sense) is, therefore, value assessment. ${ }^{6}$ This step involves many stakeholders and its importance is seen across many instances of the conservation process (Avrami et al., 2000), as it helps to determine the relative significance of the cultural heritage item (why is it important, and for whom?) as well as the measures to be applied. Value assessment is, however, rather complex, especially as "the values of certain stakeholders may conflict with those of others, and values may change over time or as a result of political conditions" (Avrami, 2009, p. 179). Thus, an assessment of significance needs to be repeated each time the same item of cultural heritage undergoes any safeguarding action.

Looking at the various codes of ethics again, it is possible to see how assessing the object's significance

\footnotetext{
4 Among the many values identified, the historical, symbolic, scientific, and aesthetic values are the ones most frequently referred to in the conservation literature (Revez, 2017). The conservator Maria João Revez comments that, curiously, one of the most importance references in conservation theory from the 20th century, Cesare Brandi, only recognizes the importance of historical and aesthetic values in conservation decision-making (Revez, 2017). For an expanded study on values in cultural heritage and conservation see Applebaum, 2009; Avrami et al., 2000; Avrami, 2009; Muñoz Viñas, 2005; and Revez, 2017. For an historical perspective on values in conservation see (Berducou, 2007).

Value-led conservation has gained many advocates in the conservation field since the turn of the millenium (see p.e. Avrami et al., 2000; Muñoz-Viñas, 2005; van de Vall, [1999] 2005; or, more recently, Ashley-Smith, 2017). Muñoz Viñas "communicative turn" also adds to this perspective.

6 It is of utmost importance to consider that any conservation endeavour is not restricted to the conservator's realm. Value assessment should be done across various spheres and through communication with multiple stakeholders.
} 
has featured only as a secondary task in conservation. Most documents are oriented towards the material properties of cultural heritage and do not provide guidelines for the assessment of their significance, nor list this task as part of the conservator's responsibilities. ${ }^{7}$ Moreover, there are various value systems that can be applied. According to Revez, Alois Riegl's framework of values is one of the most commonly used in the conservation literature (Revez, 2017). He refers to several characteristics such as historical and age and defines them according to their temporal nature as having both memory and present-day values (Riegl, [1903] 1996). Riegl also suggests that every conservation action implies choosing one set of values of relative importance over, or instead of another. As mentioned earlier, the philosopher Renée van de Vall thus suggests that every choice is "tragic" (van de Vall, [1999] 2005), as enhancing a given value will imply the loss of others.

A conservation decision has potential effects on value-attribution which can then vary with the degree and type of intervention proposed. Several values need to be taken into account, including historical, aesthetical, use, or scientific values, among others. These values are expressed through spatiotemporal contexts and, as such, value attribution is always contextual. Following the reasoning outlined by Joel Taylor and May Cassar, a decision to renew the building at António Maria Cardoso Street, could be a good solution for enhancing economic, aesthetic, and even utility values (Taylor \& Cassar 2008). It can, however, jeopardise the symbolic, historical, and research value of the building. This loss is even more dramatic if the commemorative plate remains ambiguous about the role of the building in recent history. In a session in Aljube's Museum in 2017 (in a context of a cycle of talks regarding the intangibilities of Cultural Heritage), one of the participants recalled that he had seen various historical documents dispersed onto the building's floor the day before the construction began. In this case, the alienation of the memory of the building also took the shape of a loss of its physical archive.

Decisions, however, have to be made, and built heritage, especially when lacking public protection is more prone to change than a piece of visual arts that has entered the public sphere. In the case of António Maria Cardoso Street, an optimal decision would lie in the equilibrium between the safeguarding its symbolic and historical value while reasserting its utility value - that is, transforming it in a residential complex, without erasing the memory of past events. Optimal situations, however, are rare, and conservation needs to look for ways to search for an equilibrium between what can be saved and what will be irretrievably lost. As suggested by Salvador Muñoz Viñas (2009), we need to look for a balanced meaning-loss and opt for interventions that maintain the largest area of values as possible, thus ensuring the minimal loss of meaning. An optimal situation for the evaluation of values would encompass various perspectives on the relative importance of each value. However, as the example above indicates, often a singular point of view is taken to ascribe the values involved in

\footnotetext{
This tendency is also seen in regard to other texts: Nicholas Stanley-Price, M. Kirby Talley Jr. and Alessandra Melucco Vaccaro's seminal book Historical and Philosophical Issues in the conservation of Cultural Heritage (1996), for example, gathers excerpts from texts by relevant authors such as Ruskin's The Seven Lamps of Architecture (1849), Brandi's Theory of Restoration (1963), Erwin Panofsky' History of Art as a Humanistic Discipline (1955), Philippot's Restoration from the Perspective of the Social Sciences (1989), among others. This book provides an historical perspective on issues in conservation, but also allows a brief overview of how cultures of practices have changed across disciplinary perspectives. The book by Alessandro Conti A History of the Restoration and conservation of Works of Art is also worth exploring in this context.
} 
the proposed treatment, here in the case of the renewal of the number 22 of António Maria Cardoso Street, in Lisbon. So, how can decisions be made about which values are to be taken into account, and which are considered less relevant in a given context? How to assess the values of the cultural heritage from beyond a singular perspective, and how does conservation doctrine acknowledge those different perspectives?

\section{Multiplicity of values and authorised heritage discourse}

An analysis of the various official documents and charters of conservation shows that the path towards the acknowledgement of intangible expressions of cultural heritage, as well as of the intangible features of tangible cultural heritage, was concomitant (Vecco, 2010). Marilena Vecco (2010), in her seminal article about this theme, provides a critical overview of the path towards the acknowledgement of intangible cultural heritage in official documents. However, a discussion on how these documents affect and are affected by conservation discourse is yet to happen.

Some documents discuss cultural heritage items as monuments. The Venice Charter, for example, posits heritage in association with historic monuments, stating that these objects "remain to the present day as living witnesses of their age-old traditions", characterising them as "common heritage" and their safeguarding as a "common responsibility" (ICOMOS, 1964). In 1972, UNESCO's Convention on the protection of world, cultural and natural heritage still adopts that terminology by defining cultural heritage as monuments, groups of buildings, and sites (UNESCO, 1972). The notion of monuments in use is, however, somewhat limited. ${ }^{8}$ ICOMOS's The Burra Charter (adopted in 1979, last revised in $2013)^{9}$ broadens the idea of cultural heritage by introducing the idea of places of cultural significance "including natural, indigenous and historic places with cultural values" (Australia ICOMOS, 2013a, p. 1). Curiously, this 1979 document posits that the aim of conservation is "to retain the cultural significance of a place", identifying and taking "into consideration all aspects of cultural and natural significance without unwarranted emphasis on any one value at the expense of others" (Australia ICOMOS, 2013a, p. 3-4)..$^{10}$ The Burra Charter, by referring to the importance of social significance and the multiplicity of values present at each individual place of significance, thus introduces a type of value-led conservation.

\footnotetext{
$8 \quad$ Monuments are here understood as "architectural works, works of monumental sculpture and painting, elements or structures of an archaeological nature, inscriptions, cave dwellings and combinations of features, which are of outstanding universal value from the point of view of history, art or science" (UNESCO, 1972).

9 The 2013 version of the Charter was consulted for this discussion. According to Emma Waterton and her co-authors, The Burra Charter's original draft in 1979 was much indebted to the 1964 Venice Charter. The Venice Charter was criticised given its "privileging of authenticity, and fetishism of the tangible and monumental" (Waterton et al., 2006). Although the Burra Charter has been revised, at the time of their writing Waterton and her co-authors argue that although the many versions of the Charter added to its first formulation, the contents did not significantly change (ibid.). Waterton and her co-authors criticism is thus still applied to the 2013's version of the Burra Charter (ibid.)

10 In this context it is important to refer to the ICOMOS New Zealand Charter for the conservation of Places of Cultural Significance (adopted in 2012), which acknowledges the importance of conservation as "all the processes of understanding and caring for a place so as to safeguard its cultural heritage value". Those actions are based "on respect for the existing fabric [that is, physical manifestation], associations, meanings, and use of the place” (ICOMOS, 2012, p. 9).
} 
The strong correlation made between any cultural heritage manifestation and its associated heritage values introduced by The Burra Charter is even more evident in the subsequent Nara Document on Authenticity from 1994. This document expands the association between the diversity of cultural heritage manifestations and heritage values and considers values as the fundamental constituent in every item of cultural heritage. The prominence of values is evident in the sections Values and Authenticity and Definitions, which indicate that conservation actions are "rooted in the values attributed to the heritage" and consists of "all operations designed to understand a property, know its history and meaning, ensure its material safeguard, and, if required, its restoration and enhancement" (ICOMOS, 1994). In 1996, The Declaration of San Antonio added to this discussion by suggesting that "the authenticity of our cultural heritage is directly related to our cultural identity". Cultural identity, the Declaration adds, is "at the core of community and national life, it is the foundation of our cultural heritage and its conservation" (Point B1, ICOMOS, 1996). The Krakow Charter (2000), incorporates such perspectives in the conservation of Built Heritage by primarily focussing on the plurality of values that constitute notions of heritage within various communities, stating that "monuments, as individual elements of this heritage, are bearers of values, which may change in time" (ICOMOS, 2000). The idea of a multiplicity of values is enshrined in this Charter with conservation being regarded as a community action. Communities here hold power to decide not only what to preserve but also, theoretically, how to conserve. conservation is defined in the Krakow Charter as an action of a "community that contributes to making the heritage and its monuments endure". conservation is thus achieved "with reference to the significance of the entity, with its associated values" ("Annex definitions", ICOMOS, 2000, emphasis added).

Despite the advancements made with the Burra Charter, the Nara Document on Authenticity, and the Krakow Charter, a careful reading of these documents shows that the relative importance of the values that surround an item of cultural heritage is often assumed in advance of the conservation process. Historical and aesthetic values are profusely referred to whereas other values, such as symbolic or use value appear less often. ${ }^{11}$ Enhancing such values over those others might imply the predominance of western value systems over a more pluralistic view that includes other social systems, practices, or constructions, building on what Critical Heritage Studies theorist Laurajane Smith calls "authorised heritage discourse" (Smith, 2006).

According to Smith, authorised heritage discourse occurs where narratives regarding what cultural heritage is and how we can take care of it are "based on the western national and elite class experiences." This often reinforces "ideas of innate cultural value tied to time depth, monumentality, expert knowledge and aesthetics" (Smith, 2006, p. 299). According to Smith, for something to qualify

\footnotetext{
11 According to Meredith Walker and Peter Marquis-Kyle The Burra Charter revisions aimed to broaden the definition of cultural heritage, along with "the conception of cultural significance to include not only fabric but also use, associations and meanings." (Walker \& Marquis-Kyle, 2004, p. 4). For Waterton et al., however, "while it is important to acknowledge that the revision of The Burra Charter forms part of an attempt to incorporate changing attitudes to community inclusion, participation and consultation, this attempt remains largely unsuccessful" (Waterton et al., 2006, p. 341). The main reason for The Burra Charter's incapacity to operate, according to these authors, lies in the interstices of the Charter's discourse, which perpetuates forms of power.
} 
as heritage is a cultural process strongly tied to power struggles (Smith, 2006; see also Harvey, 2001). Different narratives about what constitutes heritage compete for legitimisation, and this is more often than not sanctioned by and for those agents who hold the most power, including international and national agencies such as ICOMOS and UNESCO (or ICOM), along with states or municipalities. ${ }^{12}$

Taking Smith's perspective into account and following the analysis of conservation's codes of ethics as well as UNESCO's documents, it appears that practices of conservation (in the broad sense) reiterate the value systems aligned with "authorised heritage discourses", which are developed and maintained by the "heritage regimes" (Geismar, 2015) that hold deliberative power. Because value assessment is consigned to decisions about what is to be considered cultural heritage rather than about how to conserve the cultural object, significance assessment seems to not be directly linked to the practice of conservation, but to the choice regarding what is to be conserved. Although conservators play an active role in deciding cultural heritage materialisations, as discussed above, until recent years their role as it is expressed in conservation documents appears to have been confined to the tangible aspects of the object rather than on its intangible aspects or the realm of the values that might otherwise constitute it as cultural heritage. As it is well known that does not happen in practice, where conservators must decide on how the artwork or cultural object is to be preserved and shown.

Allied to a lack of proper tools for making value assessment to facilitate the negotiation between multiple stakeholders (Avrami et al., 2000; Revez, 2017), conservation's focus on the material aspect of cultural heritage jeopardises the safeguarding of the wider set of values associated with the particular item of cultural heritage. ${ }^{13}$ But if the social context of cultural heritage is the key in determining its significance, thus being the aim of conservation, why is conservation so concerned primarily with the object's tangibility? And what is the aspect of cultural heritage that conservators are supposed to conserve? Moreover, considering that any item of cultural heritage is characterised by the values ascribed to it, which are defined by communities and by specific individuals, then is not all cultural heritage intangible?

That is the view of recent studies on cultural heritage, especially in Critical Heritage Studies. Using 'cultural heritage' as a verb instead of a noun (Harvey, 2001), it is defined as a communicative social

12 Some critics of Smith's definition state that the Burra Charter, for example, represents a shift into value-led ways of seeing and using heritage. The Burra Charter was produced by UNESCO, which is one of the institutions Smith claims delegitimises different viewpoints regarding cultural heritage and heritage practices. Smith and her co-authors Gary Campbell and Emma Waterton posit that the charter is still very much focused on the tangible aspects of cultural heritage. Moreover, using what they call "critical discourse analysis", they conclude that "although laudable and sincere attempts have been made to incorporate a greater sense of social inclusion and participation in the Charter's revision, the discursive construction of the Burra Charter effectively undermines these innovations (...). Whether the construction of the discourse is an active attempt to maintain the privileged position of expertise in management and conservation processes or is an unintended outcome of a naturalised and self-referential approach, is no longer at issue." (Waterton et al., 2006, p. 355).

13 Authors such as Miriam Clavir (1994, 2009), Johnathan Ashley-Smith (2000, 2009), Henderson and Nakamoto (2016) or Joel Taylor (2015), among others, have reached this same conclusion. One of the Burra Charter's later practice notes, Practice Note on Understanding and assessing cultural significance (Australia ICOMOS 2013b), is also worth consulting regarding this. 
practice (Dicks, 2000; Smith, 2006), performative in itself(Haldrup \& Bærenholdt, 2015), metaculture, ${ }^{14}$ and a process of negotiation between acts of remembering and forgetting instantiated by variously conflicted actors (for example see Smith, 2006). As mentioned before, because cultural heritage is constituted by the heritage values derived from social and cultural narratives (and counternarratives), it is a discursive practice which has multiple facets. Acknowledging that cultural heritage is a process in continuum, and an embodiment of cultural narratives (whether authorised or not), it is thus important to ask whether binaries such as tangible-intangible, palpable-impalpable (at the core of the terminology used in the conservation field) still make sense. Indeed, in the introduction to Intangible Heritage, Laurajane Smith and Natsuko Akagawa question precisely the "utility of the polarising debate between 'tangible' and 'intangible' heritage", suggesting that "heritage only becomes 'heritage' when it becomes recognisable within a particular set of cultural or social values, which are themselves 'intangible"' (Smith \& Akawaga, 2009, p. 6). They further add:

Any item or place of tangible heritage can only be recognised and understood as heritage through the values people and organisations like UNESCO give it - it possesses no inherent value that 'makes' it heritage (...). All heritage is intangible, not only because of the values we give to heritage, but because of the cultural work that heritage does in any society.

Conservator and theorist Joel Taylor also adds to this discussion by suggesting that conservation has been focused on the idea of heritage as "the object, the embodiment", while, drawing on the idea that heritage "is not the object or material itself, but the reason that the object is conserved", "a site does not need to be tangible to embody value" (Taylor, 2015, p. 6). This condition of cultural heritage suggests a paradigm shift from "a cognitive movement from a form of episteme (or way of knowing) centred on objects towards one with an emphasis on living processes and manifestations" (Machuca, 2013, p. 61). In this sense, if Cultural Heritage is comprised by the values that make it Cultural Heritage, communities are at the core of the makings of those manifestations. This change in perspective has implicit and explicit consequences in the workings or, using a term coined in the field of conservation by Vivian van Saaze, the doings of conservation (van Saaze, 2013).

\section{The doings of conservation: who is called to the decide?}

The doings of conservation usually start with the identification of the main stakeholders. Communities, together with owners, public bodies, architects, historians, and conservators, for example, can be included. Indeed, several cases in the conservation literature refer to community consultation, without specifying how they define "community", nor how any such consultation process could work (see Henderson \& Nakamoto, 2016). According to Museum Studies Scholar Jennifer Barrett (Barrett, 2012) what can be understood by "community" is a fluid and contextual concept. Often related to an idea of "place", in addition to a correlation with "sharing", Barrett concludes that there is however no consensus about what this term means (ibid.). If we acknowledge that "community" is

${ }_{14}$ Referring to Barbara Kirshenblatt-Gimblett's notion of heritage as metaculture (Kirshenblatt-Gimblett, 2004), Helaine Silverman suggests "heritage is culture speaking about culture and revealing the continuities and discontinuities in the social, political, economic and other processes and reconfigured space and time that create and represent it" (2015, p. 70). 
a group of people that share something, it is possible to propose that one of the "communities" that matters for conservation efforts is a group of people that share an interest in the object, whatever that interest might be. conservation literature on community/ies engagement, however, shows that the communities have a peripheral role in conservation's decision-making process. While a systematic study of the collaboration between artists and communities, by Jane Henderson and Tanya Nakamoto, shows that the conservation literature reports instances of community engagement in the care of artworks or objects (Henderson \& Nakamoto, 2016), they make it clear, however, that in current conservation practice, consultation with those dominant stakeholders such as the owner, "experts" (as defined by Muñoz Viñas, 2005), and, sometimes artists, has precedence over consultation with any wider community. In their study, Henderson and Nakamoto conclude that, although there seems to be effective communication regarding the values of cultural heritage, when "consultation strays into the aspects of conservation practice and decisions that impinge on the physical manifestation of the object there is less ease with the community" (Henderson \& Nakamoto, 2016, p. 77). And when there is interaction with communities on the preservation of objects, details of the interaction (such as the methodology used to understand communities' expectations) remain absent from the conservation documentation that is associated with the object in the future (Henderson \& Nakamoto, 2016, p. 75; referring to Sloggett, 2009).

Acknowledging that documentation is always partial, it is important to understand what is missing when discussing the issue of stakeholders and decision making. Where absent from the conservation decision-making process and from any conservation documentation produced around an object, building, or site, the communities that surround the work are left out of the systems of power so that other stakeholders are privileged with a stronger voice and can dominate the process (Waterton \& Smith, 2010). On the other hand, the concept of "community" is very heterogeneous, and if some of the social groupings can be easily be identified due to the development of formal or informal associations, in other instances stakeholders are impossible to identify and thus to be reached in an effective manner (Waterton \& Smith, 2010). But then the question is raised as to how does such an imbalance in participation in the decision-making process affect the preservation of cultural heritage? ${ }^{15}$ Can the decision to conserve be effectively shared?

\section{Experts and authorised heritage discourse}

Conservation scientist Stefan Michalski argued in 1994 that we share the responsibility for conservation decisions with many other human and non-human agents (Michalski 1994). Studies regarding sharing with "museum outsiders" (as Michalski calls them - 1994, p. 255) are, however, in his perspective, rare. Michalski's account, which draws deeply on texts from new museologists, focuses on communities' collaboration regarding the conservation of cultural objects from "forgotten people". Also within the field of conservation, the philosopher and conservator Iris Kapelouzou indicated in 2012 that conservation decisions are inherently shared; she states that conservation "should be conceived as a field of shared values and commonality of aim" (2012, p. 181). Kapelouzou proposes

15 For a conservators' account on how community consultation happens in practice see (Johnson et al., 2005). 
that conservation, as a value-led humanistic practice, needs to consider the values associated with cultural heritage, which are in themselves associated with a shared value system. With this perspective, the conservator, along with other experts, is then seen as a representative of present generations, with whom he/she shares the values associated with current cultural heritage manifestations. However, we saw how Laurajane Smith, one of the most renowned scholars in the field of Critical Heritage Studies, argues that heritage is "exclusionary and it is intentionally so" (Smith, 2009, p. 2), and that the idea of universal values tends to reflect Western views of what is cultural heritage and, by association, how it is preserved. In this sense, she calls authorised heritage discourse (AHD) the westernised tendency to protect material culture "deemed to be of innate and inheritable value" (ibid.), with the heritage process functioning under a "monolithic" interpretation. In this sense, heritage becomes a legitimising device, granting authority to some cultural and social values and thereby excluding all Others. Indeed, Smith argues that because of such authorised discourse, its inclusions and exclusions influence the way heritage is preserved for future generations:

The AHD focuses attention on aesthetically pleasing material objects, sites, places and/or landscapes that current generations must care for, protect and revere so that they may be passed to nebulous future generations for their 'education' and to forge a sense of common identity based on the past. The idea that the value of material culture is innate rather than associative is securely embedded in this discourse. Heritage is also seen as fragile, finite and non-renewable and thus rightly under the care of those experts best placed to stand in as stewards for the past and to understand and communicate that value of heritage to the nation - principally archaeologists, architects and historians. (Smith, 2009, p. 3).

In her analysis, which mostly refers to monuments and sites, experts are then considered as representatives of this authorised heritage discourse. In conservation, Muñoz-Viñas describes conservation actions as acts of taste (Muñoz-Viñas, 2005, p. 107), which are influenced by the notion that the conservator has about the object's true nature and will necessarily influence the decisions he or she will make in order to "re-create that condition in a given way" (Muñoz-Viñas, 2005, p. 108). conservation discourse affects not only the non-specialist but also other professionals. Conservators are involved in shaping the discourse addressed around the work, and thus in the materialisations of these works from the past, in the present, for the future. Moreover, being prone to the same cognitive biases (Marçal et al., 2014), fostered by commonalities in both education and work ethos, conservators' decisions, especially when made without consulting with interdisciplinary teams, could tend to promote the authorised heritage discourse. Decisions are made influenced by cognitive and cultural biases, and thereby frame heritage research and conservation in line with mainstream ways of seeing and consuming cultural heritage. ${ }^{16}$ In conservation, this is seen in the disambiguation between material and discursive practices. Arguably the mattering of cultural heritage is constructed through the same dominant voices (curators, historians, etc.), which not only proceed in materialising the same heritage discourse but also influence how heritage is represented to its audiences. This idea echoes some concerns of the Performance Studies scholar Diana Taylor who opposes archive and

16 Curiously, this tendency was somehow foreseen by Marc Guillaume in his La politique du patrimoine, first published in 1980 (Guillaume, [1980] 2003). The author starts his reasoning by associating the politics of cultural heritage to the act of deciding what and how to conserve, and then to the idea of heritage commodification. 
the repertoire by considering the first as an embodiment of phallocentric and western-based views of what can be considered a cultural manifestation (Taylor, 2003). In this sense, conservation might be a vehicle to perpetuate the logic of the archive, affirming and reaffirming cultural historical narratives, made and pursued by the elite in power. Heritage thus seems destined to be forever static and controlled with conservation as a vehicle for maintaining and preserving its authorised mattering. Indeed, Laurajane Smith suggests that even the "idea of inheritance is also stressed and ensures that current generations are disengaged from an active use of heritage." (Smith, 2009, p. 3). conservation, as a process of transmitting intangibilities about cultural heritage, becomes also a negotiation between the included and excluded, between reconciling the Self and Others.

Going back to the idea of sustainability, or perhaps, in this case, the ability to sustain affects and memories within the fabric of the city, it is possible to say that the strategy used in the doings of the building at António Maria Cardoso Street, in Lisbon is an example of community alienation and misrecognition that might even become an impediment to the future remembrance of the place. ${ }^{17}$

\section{Community misrecognition in the public sphere}

In the article The recognition and misrecognition of community heritage, Laurajane Smith and Emma Waterton explore how community recognition is needed in order to reach fairer heritage practice (Waterton \& Smith, 2010). This could be a matter of thinking about the ethics of the conservation process, and, acknowledging that cultural heritage is something that belongs to all, it is possible to consider it in a public realm, or public sphere.

According to Don Mitchell (Mitchell, 1995, p. 117), this term, coined by the sociologist and philosopher Jürgen Habermas (Habermas, 1964), refers to a realm in which democracy occurs. ${ }^{18}$ Waterton and Smith develop their theory through critical theorist Nancy Fraser's notion of parity of participation and her ideas about "actually existing democracy" (Fraser, 1990, p. 56). According to Fraser, not only are publics (in the broad sense of the term) differently "empowered or segmented", with some, "involuntarily (...) subordinated to others", but that this inequality is often invisible within these publics (Fraser, 1990, p. 77). In this context, social justice, which according to Fraser "requires social arrangements that permit all (adult) members of society to interact with one another as peers" (Fraser, 2003, p. 36), is absent from most areas of society. This notion, the parity of participation, ${ }^{19}$ is at the core

\footnotetext{
17 This analysis was also made taking participatory performance works into account. For more see Marcal \& Macedo, 2017.

18 In her analysis of the emergence of the "public sphere" Jennifer Barrett indicates that while "Habermas repeatedly uses the term 'public sphere", the author "does not elaborate on its spatiality in either material or theoretical sense" (Barrett, 2012, p. 18).

19 Although Fraser does not explore the term "participation", her feminist-socialist roots are very much embedded in her argument. For more on Fraser's feminist and socialist views on power see Unruly Practices: Power, Discourse, and Gender in Contemporary Social Theory (Minneapolis: University of Minnesota Press, 1989).
} 
of Fraser's theory of social justice ${ }^{20}$, with its main challenges maldistribution, misrecognition, and the injustices of representation ${ }^{21}$ (Fraser, 2003). Given the scope of this paper and the nature of previous studies developed in the field of Critical Heritage Studies (Waterton \& Smith, 2010), the focus here is community misrecognition. ${ }^{22}$

According to Fraser, misrecognition is a problem that "denies some individuals and groups the possibility of participating on a par with others in social interaction" (Fraser, 2001, p. 27). Drawing on Fraser's perspective as explored by Waterton and Smith (2010), it becomes evident that communities are misrecognised in conservation's decision-making process. Either by failing or not trying to identify possible representatives or advocates within communities, or by making their accounts about the work invisible, or even by transforming communities into consultants, conservation efforts (made either by conservator or not) might be complicit in withdrawing power from these stakeholders. That was what happened with the building at António Maria Cardoso Street, in Lisbon. Moreover, as Nancy Fraser tells us that those "whose deliberative practice consists exclusively in opinion formation and does not encompass decision-making" cannot claim to have real influence (Fraser, 1990, p. 75). Communities' misrecognition also ensures their de-legitimisation in other processes within the public sphere. As communities lack recognition along with deliberative practice, more than being misrecognised, they remain unrepresented in the decisions about cultural heritage that is, in fact, theirs. In this sense, efforts put into place to categorise, inventory, and conserve cultural heritage might fall flat, as communities grow apart from the fabric that constitutes their past and their own cultural heritage. With regard to the conservation of cultural heritage, despite the efforts made in the development of The Burra Charter and Nara Document on Authenticity, the cultural value ascribed to communities is not yet seen on a par with those of institutional expertise. Through Fraser's analysis it is possible to understand that this imbalance in participation creates at least two problems: (1) the voices of each present generation is successively being forgotten, and (2) it increases the potential for antagonism between different publics and for what is declared as cultural heritage since it compromises the identification that communities might feel towards a work. And yet, as Fraser's notion of justice suggests, as users of cultural heritage,

${ }^{20}$ In her analysis, Fraser demonstrates how parity of participation differs from the idea of social inclusion. The political scientist states that social inclusion was a term that emerged as a way to control potential disruptive individuals (Fraser, 1989). As it will be made clearer, participation, for Fraser, includes decision-making. Art historian Claire Bishop also makes a distinction between participation and social inclusion, suggesting that "social inclusion" is embedded in political discourses aiming at maintaining the status quo while making individuals accept their place in a highly stratified society: "Incorporated into New Labour's cultural policy, the social inclusion discourse leaned heavily upon a report by François Matarasso proving the positive impact of social participation in the arts. (...) social participation is viewed positively because it creates submissive citizens who respect authority and accept the 'risk' and responsibility of looking after themselves in the face of diminished public services. As the cultural theorist Paola Merli has pointed out, none of these outcomes will change or even raise consciousness of the structural conditions of people's daily existence, it will only help people to accept them" (2012, p. 14). A deeper analysis on the issue of participation needs to necessarily render a comparison between these two concepts. This discussion is however a subject for further work.

${ }_{21}$ Fraser's account on injustices of representation is indebted to previous studies about power and social representation, namely to the work of Michel Foucault and, more recently, Judith Butler (see Butler, 1993).

22 It is important to mention, however, that community misrecognition in the case of Cultural Heritage also implies lack of access to resource distribution. 
communities should also have a co-responsibility for its preservation. As it will become clear, the case of Aljube's prision, on the other hand, provides an excellent case-study on how memories can be collected and remmembered through the assessment of various perspectives.

\section{Parity of participation: conservation in the public sphere}

During the public talk at the Aljube's prison (now Aljube's museum) we discussed the renewal of the building with the people attending the event. Some of those people knew the building since it was still a prison. One of the participants recalled that the event was the first time they had entered the building, as it was always emanating the aura of the past: "I could not even look at it", the participant recalled. Other participant spoke about how the grids in the windows, or the black curtains in the room, made him remember the past, as a resonance of the previous life of the building. The objectification and fetishization of the past were also a theme during this conversation, with a museum's employee evoking that some people ask to be put in one of the small cells just to be able "to feel how it was like". These views provide a summary on the possibilities around involving communities in the making of meaning of a building or historical site. The restoration of the building allowed people to continue to identify the building as a prison, potentiating storytelling practices around the memories of the place. Aljube's museum has been a pioneer in the collection of stories and biographies by people who were placed in the prison, along with other people who opposed the regime. The identification those communities - i.e. the people who live in Lisbon, visit Aljube, or somehow contribute to Aljube's repository of memories - is also promoted by their recognition.

This notion of community, perhaps somehow more inclusive, leaves conservation decision-making in a conundrum: being inclusive here arguably equates with becoming unmanageable. Indeed, although it would be possible for conservators to promote a participative action, by creating multiple open, physical and virtual fora where individuals from different communities could directly engage into the conservation process of a given object, that would inevitably raise some problems:

(1) creating an issue with community representation as different communities may not be equally represented in the process;

(2) making conservation processes more time consuming;

(3) increasing the costs of conservation actions due to the employment of more (and more specialised) human resources in order to analyse the data;

(4) transforming any conservation act into an openly political action, as many voices (the ones that would argue for the objects destruction, for example) would probably not be considered, leading to an open process of censorship.

Notwithstanding these problems, communities still need to be recognised as a legitimate stakeholder in order to promote a more just and diffracted decision-making process. In this sense, present generations are involved in the process of mattering collective and individual memories in their everyday life so their involvement in documentation could, considering Barad's account, provide a corpus of diffracted perspectives which resonate across the materiality and (historical) discourse about the work. Moreover, 
by incorporating a diversity of ways of knowing buildings or sites, new material potentialities can emerge from the many different mattering processes. In embodying the idea of intergenerational justice (see Taylor, 2013), this idea makes visible the role that present generations need to have in the preservation of material manifestations of cultural heritage. It is important to acknowledge the limitations of any decision-making process, including the misrepresentation of communities. Such acknowledgement can take form in the work's documentation such that by documenting all decisions, ${ }^{23}$ and including all stakeholders involved in decision-making, and including any engagement process, conservators in the present can make sure that future generations can make more informed and sustainable decisions, linking the past of the object to its future.

\section{Conclusion}

This paper discussed how public engagement could make conservation efforts more sustainable. While discussing the lack of inclusion in some conservation processes, it has argued that community misrecognition happens in conservation decision-making. This paper also suggested that it is possible to acknowledge the diverse and partial nature of documentation while recognising that some stakeholders have inevitably been missed in the process by including diffractive content from the decision-making process in any documentation file. Laurajane Smith's notion of authorised heritage discourse provided the ideal framework to diagnose the process that led to the renewal of the building at António Maria Cardoso Street, in Lisbon as a process with where communities were alienated. In this sense, this paper also reflected upon how participation from communities could ensue the development of narratives that sustain the memories around a building or site. This issue is even more important taking into account the historical context that led to the transformations that occurred in those two buildings. Enhancing community participation might be a way to make visible the nuances of a time of political strain and its aftermath of historical erasure.

Finally, although this paper explores the issue of sustainable heritage approaches in a different way, there is still much to explore regarding inclusiveness and parity of participation in heritage contexts. The same could be said about practical ways of engaging with communities and enhancing communities' participation in conservation's decision-making processes. Given that "communities" is still an ambiguous notion, a systematic study about communities' participation might need to be precluded by a theoretical examination. The association between "communities" and "place" provides a good starting point for this discussion. Shifting the focus from museums or centralised governmental and non-governmental institutions into local institutions and municipalities will allow for a geographical delimitation of cultural heritage communities. In this sense, pilot projects, such as the COMUS project "Community-Led Urban Strategies in Historic Towns", could help find ways to enhance community participation through practice. The role of digital communities is also a topic of interest for future studies regarding community mis/recognition (the programme "Sharing is Caring", developed by the SMK Denmark is worth mentioning as a point of departure).

23 See Jonathan Kemp's Practical Ethics v2.0, where he gives examples about decisions which were made outside what is usually considered the conservation scope and yet influence the conservation process (Kemp 2009). 


\section{Acknowledgements}

This paper was supported by the Fundação para a Ciência e Tecnologia (SFRH/BD/90040/2012). A special thank you to my supervisor Rita Macedo for all the meaningful and intellectual exchanges without which this research would not be possible. 


\section{Bibliography}

Appelbaum, B. (2009) Conservation treatment methodology. Oxford: Butterworth-Heinemann AIC (1994). Code of Ethics and Guidelines for Practice, The Association (AIC). Available at: http://www. conservation-us.org/our-organizations/association-(aic)/governance/code-of-ethics-and-guidelinesfor-practice/code-of-ethics-and-guidelines-for-practice-(html)\#.W8XzemhKiUk (accessed in 12.09.2018)

AIC (2018). Sustainability Committee, Publication \& Resources. Available at: http://www.conservationus.org/specialty-topics/sustainability\#.W8WuNGhKiUk (accessed in 12.09.2018)

AICCM (2002). Code of Ethics and Code of Practice. Available at: https://aiccm.org.au/sites/default/ files/docs/AICCMBusinessDocs/CODE\%200F\%20ETHICS\%20AND\%20CODE\%20OF\%20 PRACTICE\%20Australian\%20Institute\%20for\%20conservation\%20of\%20Cultural\%20Material.pdf (accessed in 12.09.2018)

Ashley-Smith, Jonathan (1999). Risk Assessment for Object conservation. London: ButterworthHeinemann

Ashley-Smith, Jonathan (2017). A role for bespoke codes of ethics. In Bridgland, Janet (ed.), ICOMCC 18th Triennial Conference Preprints, Copenhagen, 4-8 September 2017, ed., art. 1901. Paris: The International Council of Museums.

Australia ICOMOS (2013 [1981]). Burra Charter, Australia Charter for the conservation of Places of Cultural Interest. Burra: ICOMOS.

Australia ICOMOS (2013). Practice Note. Understanding and assessing cultural significance, Version 1: November. Burra: ICOMOS. Available at: http://australia.icomos.org/wp-content/uploads/PracticeNote_Understanding-and-assessing-cultural-significance.pdf (accessed in 18.08.2017).

Avrami, Erica (2009). Heritage, Values, and Sustainability. In Richmond, Alison; Bracker, Alison (ed.): Conservation: Principles, Dilemmas and Uncomfortable Truths, p. 184-196, London: ButterworthHeinemann.

Avrami, Erica; Randall Manson; and Marta de la Torre (ed.) (2000). Values and Heritage conservation. Research Report, Los Angeles: The Getty Foundation.

Barrett, Jennifer (2012). Museums and the Public Sphere, West Sussex: Wiley.

Berducou, Marie (2007). Cultural heritage values and conservation: a historical perspective. In VaroliPiazza, R. (ed.), Sharing conservation Decisions, Rome: ICCROM.

Boaventura, Inês (2014). Câmara de Lisboa apresentou queixa pelo roubo de placa da antiga sede da PIDE. In Público (2 April 2014, 13:11). Available at: https://www.publico.pt/2014/04/02/local/ noticia/ camara-de-lisboa-apresentou-queixa-pelo-roubo-de-placa-da-antiga-sede-da-pide-1630701 (accessed in 17.02.2017).

Bracker, Alison; Richmond, Alison (2009). Introduction. In Bracker, Alison; Richmond, Alison (ed.): Conservation: Principles, Dilemmas and Uncomfortable Truths, p. i-xvii, London: ButterworthHeinemann. 
CAC and CAPC (2010). Code of Ethics and Guidance for Practice of the Canadian Association for conservation of Cultural Property and of the Canadian Association of Professional Conservators. Available at: http://www.cac-accr.ca (accessed in 17.02.2017).

Cane, Simon (2009). Why Do We Conserve? Developing Understanding of conservation as a Cultural Construct. In Bracker, Alison; Richmond, Alison (ed.) Conservation: Principles, Dilemmas and Uncomfortable Truths, p. 163-176, London: Butterworth-Heinemann.

Clavir, Miriam (1994). Preserving Conceptual Integrity: Ethics and Theory in Preventive conservation. In Preprints, IIC Congress, Preventive conservation: Practice, Theory and Research, Sept 12-16, p. 53-57. Clavir, Miriam (2009). Conservation and Cultural Significance. In Bracker, Alison; Richmond, Alison (ed.) Conservation: Principles, Dilemmas and Uncomfortable Truths, p. 139-149, London: ButterworthHeinemann.

de Silva, Megan \& Henderson, Jane (2011). Sustainability in conservation practice. Journal of the Institute of conservation 34 (1), p. 5-15.

Dicks, Bella (2000). Heritage, Place and Community. Cardiff, University of Wales Press.

ECCO (2003). E.C.C.O. Professional Guidelines (II). Available at: http://www.encore-edu.org/ecco2. html (accessed in 17.02.2017).

Fraser, Nancy (1990). Rethinking the public sphere: A contribution to the critique of actually existing democracy. Social Text 25/26, p. 56-80.

Fraser, Nancy (2001). Recognition without ethics?. Theory, Culture \& Society, 18(2-3), p. 21-42.

Fraser, Nancy (2003). Social justice in the age of identity politics: Redistribution, recognition and participation. In Fraser, N.; Honneth, A. (eds.) Redistribution or recognition? A political-philosophical exchange, Verso: New York.

Geismar, Haidy (2015). Anthropology and Heritage Regimes. Annual Review of Anthropology 44(1), p. 71-85. https://doi.org/10.1146/annurev-anthro-102214- 014217

Guillaume, Marc ([1980] 2003). La Politique du patrimoine, Paris: Editions Galilée.

Habermas, Jürgen (1974). The public sphere: An encyclopedia article, P. U. Hohendahl (trans.). New German Critique 3, 1964, p. 45-8.

Haldrup, Michael \& Bærenholdt, Jørgen Ole (2015). Heritage as Performance. In Waterton, E.; Watson, S. (ed.) The Palgrave Handbook of Contemporary Heritage Research, 52-68. London: Palgrave Macmillan.

Harvey, David C. (2001). Heritage pasts and heritage presents: Temporality, meaning and the scope of heritage studies. International Journal of Heritage Studies, 7 (4), p. 319-38.

Henderson, Jane \& Nakamoto, Tanya (2016). Dialogue in conservation decision-making. Studies in conservation 61(2), p. 67-78 (doi: 10.1080/00393630.2016.1183106).

ICOM (1984). The Conservator-Restorer: a Definition of the Profession. Available at: http://www.icomcc.org/47/\#.UXCITo5pugE (accessed in 10.08.2017). 
ICOM-CC (2008) Terminology to Characterize the conservation of Tangible Cultural Heritage. Available at: http://www.icom-cc.org/242/about-icom- cc/what-is-conservation/\#.Vz9ZBSN97mE (accessed in 20.10.2016).

ICOMOS (1964). International Charter for the conservation and Restoration of Monuments and Sites (Venice charter) [online]. Available at: http://www.icomos.org/charters/ venice_e.pdf (accessed in 04.02.2015).

ICOMOS (1994). Nara Document on Authenticity [online]. Available at: http://www. icomos.org/ charters/nara-e.pdf (accessed in 04.02.2015).

ICOMOS (1996). Principles for the recording of monuments, groups of buildings and sites. Available at: http://www.icomos.org/charters/archives-e.pdf (accessed in 04.02.2015).

ICOMOS (2000). Principles for the conservation and Restoration of Built Heritage (The Krakow Charter). Available at: http://smartheritage.com/wp-content/uploads/ 2015/03/KRAKOV-CHARTER-2000.pdf (accessed in 14.08.2017).

Taylor, Joel (2013). Intergenerational justice: A useful perspective for heritage conservation. CeROArt [online], Cultures of conservation. Available at: http://ceroart.revues.org/3510 (accessed 21.10.2016).

Taylor, Joel (2015). Embodiment unbound: Moving beyond divisions in the understanding and practice of heritage conservation. Studies in conservation, 60 (1), p. 65-77.

Kapelouzou, Iris (2012). The Inherent Sharing of conservation Decisions. Studies in conservation, 57 (3), p. 172-182.

Kirshenblatt-Gimblett, Barbara (2004). Intangible Heritage as Metacultural Production. Museum International 221-222, 56 (1-2), p. 52-65.

Machuca, Jesús Antonio (2013). Challenges for Anthropological Research on Intangible Cultural Heritage. In Arizpe, L.; Amescua C. (ed) Anthropological Perspectives on Intangible Cultural Heritage, New York, Dordrecht and London: Springer, p. 57-70. doi: 10.1007/978-3-319-00855-4_5

Marçal, Hélia \& Macedo, Rita (2017). From the periphery to the centre of decision: community engagement and justice in conservation decision-making. In Bridgland, J. (ed.) ICOM-CC 18th Triennial Conference Preprints, Copenhagen, 4-8 September 2017, Paris: The International Council of Museums.

Marçal, Hélia; Macedo, Rita \& Duarte, António Manuel (2014). The inevitable subjective nature of conservation: Psychological insights on the process of decision-making. In Bridgland, J. (ed.) ICOMCC 17th Triennial Conference Preprints, Melbourne, 15-19 September, Paris: The International Council of Museums.

Michalski, Stefan (1994). Sharing responsibility for conservation decisions. In Krumbein, W. E.; Brimblecombe, P.; Cosgrove, D. E.; Staniforth, S. (ed.), Durability and change: the science, responsibility, and cost of sustaining cultural heritage, London: Wiley, p. 241-258.

Mitchell, Don (1995). The end of public space? People's park, definitions of public, and democracy. Annals of the Association of American Geographers 85(1), p. 108-33. 
Muñoz Viñas, Salvador (2005). Contemporary Theory of conservation. Oxford: ButterworthHeinemann.

Museu do Aljube - Resistência e Liberdade (2015). O Museu - Museu Do Aljube - Resistência E Liberdade. Available at: http://www.museudoaljube.pt/omuseu (accessed in 17.02.2017).

Oliveira, Elian (2012). Aljube, uma cadeia política. Unpublished Master Thesis, Universidade Nova de Lisboa. Available at: https://run.unl.pt/handle/10362/9390 (accessed in 17.02.2017).

Prati et al. (2017). Sustainability in art conservation: A novel bio-based organogel for the cleaning of water sensitive works of art, Pure and Applied Chemistry, 90 (2), DOI: 10.1515/pac-2017-0507

Revez, Maria João (2017). Compatibility matters: Assessing the risks of built heritage cleaning. Unpublished PhD Thesis, Lisboa: Universidade Nova de Lisboa..

Riegl, Alois (1996). The Modern Cult of Monuments: Its Essence and Its Development. In Price, Nicholas; Talley, M. K.; Vaccaro, Alessandra M. (ed.). Historical and Philosophical Issues in the conservation of Cultural Heritage, Malibu: The Getty Institute, p. 69-83.

Scholte, Tatja (2010). Um estudo comparativo sobre a conservação de obras de arte (etnográficas e contemporâneas) de localização específica. I: Macedo, R.; da Silva, R. H. (ed.). A arte efémera e a conservação: $O$ paradigma da arte contemporânea e dos bens etnográficos, Lisbon: Instituto de Historia da Arte, p. 47- 64.

Sloggett, Robyn (2009). Expanding the conservation canon: Assessing Cross-Cultural and Interdisciplinary Collaborations in conservation. Studies in conservation 54(3), p. 170-183.

Smith, Laurajane (2006). Uses of Heritage, London: Routledge.

Smith, Laurajane \& Akagawa, Natsuko (ed.) (2009). Intangible Heritage. London: Routledge.

Taylor, Diana (2003). The Archive and the Repertoire, Durham: Duke University Press.

Taylor, Joel \& Cassar, May (2008). Representation and intervention: The symbiotic relationship of conservation and value. In Saunders, D.; Townsend, J. H.; Woodcock, S.: Conservation and Access: Contributions to the London Congress, London, p. 7-11.

UNESCO (1972). World Heritage Convention, Paris: UNESCO. Available at: https://whc.unesco.org/ en/conventiontext/ (accessed in 17.10.2017).

van de Vall, Renée (2005 [1999]). Painful Decisions: Philosophical Consideration on a Decisionmaking Model. In Hummelen, Ijsbrand; Sillé, Dionne (ed.) Modern Art: Who Cares?, Amsterdam: SBMK, p. 196-200.

Vall, Renée van de, Hölling, H. B.; Scholte, T. I. \& Stigter, S. (2011) Reflections on a biographical approach to contemporary art conservation. In Bridgland, J. (ed.) ICOM-CC 16th Triennial Meeting Preprints, Lisbon, 19-23 September, Almada: Criterio.

van Saaze, Vivian (2013). Installation Art and the Museum: Presentation and Conservation of Changing Artworks. Amsterdam: Amsterdam University Press.

Vecco, Marilena (2010). A definition of cultural heritage: From the tangible to the intangible. Journal of Cultural Heritage 11, p. 321-324. doi:10.1016/j.culher.2010.01.006 
Walker, Meredith \& Marquis-Kyle, Peter (2004). The illustrated Burra Charter: good practice for heritage places. Burwood: ICOMOS.

Waterton, Emma \& Smith, Laurajane (2010). The recognition and misrecognition of community heritage. International Journal of Heritage Studies 16(1-2), p. 4- 15.

Waterton, Emma; Smith, Laurajane \& Campbell, Gary (2006). The Utility of Discourse Analysis to Heritage Studies: The Burra Charter and Social Inclusion. International Journal of Heritage Studies 12(4), p. 339-355.

Weyer, Cornelia \& Heydenreich, Gunnar (2005 [1999]). From questionnaires to a checklist for dialogues. In Hummelen, Ijsbrand; Sillé, Dionne (ed.), Modern Art: Who Cares?, Amsterdam: Amsterdam University Press, p. 385-88.

Wharton, Glenn (2005). The Challenges of Conserving Contemporary Art. In Altshuler, Bruce (ed.) Collecting the New: Museums and Contemporary Art, Princeton: Princeton University Press, p. 163178. 
